\title{
Teacher-perceived emergency disaster needs of physically and mentally challenged school children in Japan
}

\author{
Reiko KATO $^{1}$, Shiho NISHIDA ${ }^{1}$, Kafumi KOMURO ${ }^{2}$ and Chieko NUMAGUCHI ${ }^{3}$ \\ ${ }^{1}$ Kyoritsu Women's University, Tokyo, Japan \\ ${ }^{2}$ Tokyo Medical University, Tokyo, Japan \\ ${ }^{3}$ Ibaraki Prefectural University of Health Sciences, Ibaraki, Japan
}

\begin{abstract}
Aim: The purpose of this study was to describe: (i) the recognition from teachers at special support schools who experienced the Great East Japan Earthquake regarding the needs of children with physical disabilities or slight intellectual and physical disabilities to be better prepared and possess the ability to provide self-care in the event of a natural disaster; and (ii) teachers' recognition for enhancement of children's abilities through education.

Methods: This was a qualitative design that was based on a content analysis of semi-structured interviews with 15 teachers who were working at five special support schools for children with physical disabilities in two prefectures in the Kanto area, when the Earthquake occurred. Data collection was between November 2011 and August 2012.

Results: The teachers recognized that children who need to prepare for natural disasters require eight abilities of self-care: protect themselves, have a sense of emergency, prepare emergency supplies, ask for help, act in a calm way, act independently, comprehend the situation of others and the surroundings too, and prior arrangement of means of contact in an emergency. Also, there were five education methods needed to help these children act independently in such an event.

Conclusions: For these children to be able to personally prepare for natural disasters, they need to acquire and/ or enhance their abilities in terms of the eight self-care abilities derived from this study. The inclusion and application of the five education methods and evacuation drills as part of their daily life is very necessary.
\end{abstract}

Key words: children, disability, natural disaster, preparation, self-care ability

\section{INTRODUCTION}

Many lives are lost worldwide due to frequent natural disasters such as earthquakes, floods, tornados, wildfires and volcanic eruptions. The Tohoku Region Pacific Coast Earthquake occurred on 11 March 2011, causing a very large tsunami that caused a nuclear accident at the Tokyo Electric Power Company's Fukushima Daiichi Nuclear Power Plant. As a result, it is now referred to as the Great East Japan Earthquake disaster.

Correspondence: Reiko Kato, Kyoritsu Women's University, 3-27 Kanda Jinbocho, Chiyoda-ku Tokyo 101-0051, Japan. Email: rkato@kyoritsu-wu.ac.jp

Received 4 December 2013; accepted 26 March 2014.
It was one of the most devastatingly large-scale disasters in history. Currently, a series of aftershocks continue even today and the possibility of an upcoming Tokyo Metropolitan, Tokai, and Nankai Trough earthquake is increasing. In order to reduce the potential loss of life and damage, the government has introduced a disasters management plan (Cabinet Office, Government of Japan, 2011). That plan affects all citizens of Japan, including children with disabilities. During the Great East Japan Earthquake, the number of disabled people fatalities was approximately double that of non-disabled people (Disability Information Resources, 2011). Also, the number of injuries sustained by children with disabilities was more than double that of able-bodied children (Tanaka, 2013). 
In the 2012 fiscal year, the total student population of Japanese elementary schools and junior high schools was approximately 10.5 million, and there was a total student population of 130,000 who require special support (Japan Child and Family Research Institute, 2013). Despite the fact that the Japanese society is facing a steady decline in the number of children, the number of special support children is increasing due to a recent change in education policy. Of the total child population in special support schools across the country, approximately $57 \%$ have multiple disabilities. Within the special support student population of approximately 32,000 , and focusing only on those special support children with physical disabilities, $88 \%$ have multiple disabilities (Ministry of Education, Culture, Sports, Science and Technology: MEXT, 2012a).

Utilizing the lessons learnt from the Great East Japan Earthquake, the MEXT (2012b) has published " $A$ Handbook for How to Produce School Disaster Prevention Manuals". This handbook suggests the necessary improvements that are required for each school's evacuation drills, the evaluation of such drills, and the improvement of the school manual. All special support schools are also included under this.

We developed the "Disaster Simulation Package for Special Needs Schools" (Kato, Komuro, \& Numaguchi, 2008; Kato, Komuro, \& Numaguchi, 2012) and we have been actively disseminating this information to special support schools. However, the thinking behind this drive is 'Adults should protect children from natural disasters'.

In recent articles published, a doctor who experienced the disaster firsthand said that Japan needs to make use of its experiences and bring together the knowledge and skills to protect all children with disabilities (Tanaka, 2013). In America, there are studies being conducted with the focus on "children with special health-care needs". They are focusing on the preparedness of families (Baker \& Baker, 2010; Baker, Baker, \& Flagg, 2012). However, these studies are looking at all children with disabilities, and do not pay particular attention to those with physical disabilities only.

A virtual reality disaster evacuation drill system, designed especially for intellectually challenged children, has been used (Nagaoka, 2007). This resulted in such children not only being able to increase their personal ability to react in a disaster, but it also found that they were able to actually recognize such disasters for themselves. A study focusing on intellectually challenged children in special support schools was also conducted. In this study, it was found that although the drill was designed to heighten students' ability to protect themselves in a disaster and improve their ability to react, the drill was insufficient in gaining the desired outcome because it was teacher-led. It is necessary to increase the student's recognition of natural disasters and their physical abilities and capabilities to better cope in a disaster evacuation (Matsuse \& Kobayashi, 2008).

As a matter of interest, when Hurricane Katrina hit the USA, approximately 2,500 children at evacuation shelters became separated from their parents (Murray, 2011), illustrating that it is quite possible for children and their parents to become separated in the event of a natural disaster. In addition, children with special healthcare needs not only did not receive the appropriate medical care, but also, in fact, suffered from illness, hunger and even abuse at evacuation shelters after Hurricane Katrina (Peek \& Stough, 2010). Therefore, we understood that challenged children suffer particularly serious problems after such events. Even at special support schools for physically challenged children, there are many schools where it is not possible for these children to move around easily due to their physical impairment or because they are in a wheelchair. Additionally, it would become almost impossible for them to move around easily in the event of a natural disaster because the elevators would be out of service.

Besides, there are many physically challenged children who have intellectual as well as multiple disabilities, thus making it very difficult for them to protect themselves in the event of a disaster. Another issue is how they survive and cope in evacuation shelters. Apart from the difficulty of moving around by themselves, it is also a struggle for them to express their bodily needs adequately.

These days, where there are numerous types of natural disasters, it is all the more necessary to introduce measures to assist challenged children in order for them to be prepared to deal with their own individual circumstances. It is also necessary to consider and then prepare for the particular natural disaster that is most likely to occur in their area. It is necessary to make such preparations for adults to be able to protect the children, as well as for the children, so that they are able to act appropriately and help protect themselves. Therefore, it is imperative to raise the ability of challenged children to take the appropriate action and be able to evacuate as best as is possible for their individual disability (Matsuse \& Kobayashi, 2008; Nagaoka, 2007).

It is recognized that there is a need for education and drills so such children can protect themselves in the event of a natural disaster. However, only a few studies have 
ever been found that have been related to the education and evacuation drills for both physically only challenged children, as well as slightly intellectually and physically challenged children.

In two areas of the Kanto region, the disaster situation is as follows: the northern area was affected by the Great East Japan Earthquake in 2011, which measured approximately six in intensity. In the same area, there were approximately 850 buildings that collapsed or were damaged from a powerful tornado in 2012. The southern area was affected by the earthquake, which measured between 4 and 5 in intensity. Additionally, there was damage from flooding and landslides caused by a typhoon in 2013 in the same area. Furthermore, severe damage is expected in Tokyo and the Nankai Trough region within the next few decades.

The ultimate goal of our study is to develop a plan to raise the preparedness for self-care abilities of physically only challenged children, as well as slightly intellectually and physically challenged children, through the application of suitable education and drills, as well as through other methods. As part of ongoing studies, the purpose of this study is to: (i) describe the actual situation of preparation prior to the Great East Japan Earthquake; (ii) describe the actual damage suffered by special support schools for children with physical disabilities after the disaster; (iii) obtain the recognition from the teachers at special support schools who experienced the Great East Japan Earthquake regarding the need for these children to be better prepared and to acquire the abilities to provide self-care in the event of a natural disaster; and (iv) obtain teachers' recognition for enhancement of children's abilities through education.

\section{METHODS}

\section{Generation and treatment of data}

Fifteen teachers who were working at five special support schools for children with physical disabilities in two prefectures of the Kanto area participated in this study. Three of the schools were in northern Kanto and the other two were in southern Kanto. Seventy to one-hundred and thirteen children, who were first to ninth graders, were in the five schools, and 82 to $100 \%$ of them had intellectual and physical disabilities. (Table 1)

The schools, at which the participants of teachers worked, were referred to us by the education bureau of the respective prefectures. We sent request papers for participation in the research and asked the Principals of each school to nominate suitable teachers as participants.
Table 1 Participant schools

\begin{tabular}{|c|c|c|c|c|c|}
\hline \multirow[t]{2}{*}{ School* } & \multicolumn{3}{|c|}{ Number of children } & \multicolumn{2}{|c|}{$\begin{array}{l}\text { Number of children } \\
\text { with intellectual } \\
\text { and physical } \\
\text { disabilities }\end{array}$} \\
\hline & $\begin{array}{l}\text { Elementary } \\
\text { school }\end{array}$ & $\begin{array}{l}\text { Junior } \\
\text { high } \\
\text { school }\end{array}$ & Total & Total & $\begin{array}{c}\text { Percentage } \\
(\%)\end{array}$ \\
\hline A & 61 & 52 & 113 & 108 & 95 \\
\hline B & 66 & 42 & 108 & 89 & 82 \\
\hline $\mathrm{C}$ & 49 & 28 & 77 & 67 & 87 \\
\hline $\mathrm{D}$ & 49 & 23 & 72 & 72 & 100 \\
\hline E & 44 & 26 & 70 & 70 & 100 \\
\hline
\end{tabular}

${ }^{*}$ Each school has both an elementary school and a junior high school.

\section{Data collection}

A qualitative research was conducted. Data were obtained through semi-structured interviews, conducted between November 2011 and August 2012, with individual participants following an interview guide. All interviews were recorded on a recorder and ware transcribed verbatim.

\section{Interview guide}

The contents of the interview guide for this study, developed by the researchers, were as follows:

1 How and what was your school prepared for with regard to natural disasters prior to the Great East Japan Earthquake.

2 What was the school's situation at the time of the Great East Japan Earthquake disaster?

3 What situation has your school been in between the time of the Great East Japan Earthquake disaster and this interview?

4 What do you think about the necessity of preparing for a disaster by children with physical disabilities?

5 What self-care abilities do children need to prepare for a disaster?

6 What ways do you think there are for children to increase their self-care abilities to prepare for a disaster?

\section{Data analysis}

The duration of the interviews was from 30 to $64 \mathrm{~min}$, and the average was $46 \mathrm{~min}$. Transcripts from all recorded data were analyzed following the contents of the interview guide and categorized according to similarities. Qualitative researchers, who research disaster nursing and special support school nursing as sub-specialties in child health nursing, analyzed the data. To ensure trustworthiness and credibility, after several careful investigative analysis meetings were held among the 
Table 2 Participants

\begin{tabular}{|c|c|c|c|c|c|}
\hline \multirow[b]{2}{*}{ Teacher } & \multirow[b]{2}{*}{ Gender } & \multicolumn{3}{|c|}{ Teaching career (years) } & \multirow[b]{2}{*}{ Present class } \\
\hline & & $\begin{array}{l}\text { At special support } \\
\text { schools } \\
\text { (Average 16.5) } \\
\text { (Range 5-30) }\end{array}$ & $\begin{array}{l}\text { For children with } \\
\text { physical disabilities } \\
\text { (Average 7.6) } \\
\text { (Range 2-18) }\end{array}$ & $\begin{array}{l}\text { At the present school } \\
\text { (Average } 4.7 \text { ) } \\
\text { (Range 2-11) }\end{array}$ & \\
\hline A & M & 15 & 5 & 3 & Early grade of elementary school \\
\hline $\mathrm{B}$ & $\mathrm{F}$ & 12 & 5 & 2 & Late grade of elementary school \\
\hline $\mathrm{C}$ & $\mathrm{F}$ & 9 & 2 & 3 & Junior high school \\
\hline $\mathrm{D}$ & $\mathrm{F}$ & 25 & 11 & 11 & Early grade of elementary school \\
\hline $\mathrm{E}$ & M & 9 & 6 & 6 & Late grade of elementary school \\
\hline $\mathrm{F}$ & M & 9 & 8 & 6 & Junior high school \\
\hline G & $\mathrm{F}$ & 14 & 3 & 3 & Early grade of elementary school \\
\hline $\mathrm{H}$ & $\mathrm{F}$ & 22 & 10 & 5 & Late grade of elementary school \\
\hline I & M & 24 & 2 & 2 & Junior high school \\
\hline $\mathrm{J}$ & $\mathrm{F}$ & 20 & 10 & 5 & Early grade of elementary school \\
\hline $\mathrm{K}$ & $\mathrm{F}$ & 5 & 5 & 5 & Late grade of elementary school \\
\hline $\mathrm{L}$ & M & 5 & 3 & 3 & Junior high school \\
\hline M & $\mathrm{F}$ & 27 & 18 & 5 & Early grade of elementary school \\
\hline $\mathrm{N}$ & $\mathrm{F}$ & 30 & 8 & 8 & Late grade of elementary school \\
\hline $\mathrm{O}$ & M & 21 & 18 & 4 & Junior high school \\
\hline
\end{tabular}

F, female; M, male.

researchers, meetings at one of the local schools were held between seven teachers other than those already interviewed but who knew the children's situation well, and the four researchers. In the meetings, careful consideration was given to the analyzed categories and sub categories and then full agreement was obtained for the study results.

\section{Ethical consideration}

This study was conducted after obtaining approval from the Research Ethics Committee of Kyoritsu Women's University and Kyoritsu Women's Junior College, Japan. Written consent was obtained from participants after verbal and written explanations were provided regarding considerations, including privacy protection, the voluntary nature of participation, and the right to withdraw.

\section{Participants}

Fifteen participants participated in this study; nine were female and six were male. And there were five teachers in each grade grouping of early elementary, late elementary and junior high. The average and the range of teaching careers at special support schools, for children with physical disabilities, and at the present school were 16.5 (5-30), 7.6 (2-18), and 4.7 (2-11) years, for early elementary, late elementary and junior high, respectively (Table 2).

\section{Status of the schools at the time of the Earthquake}

At two of the five schools, in which a seismic intensity of six was measured, the electricity, gas and water supply stopped. At the other three schools, in which seismic intensities of four to approximately five were measured, the interruption of utility supply varied, and all had cracked or collapsed walls. Most parents were able to collect their child by the end of that day (Table 3).

\section{Disaster preparedness of the schools prior to the Earthquake}

Of the five schools, three had stockpiles of food and water, and two did not. All of the schools conducted evacuation drills twice a year for earthquake and fire, and these drills included the following: (i) all children and teachers knew the date and time of the drills; (ii) teachers led the evacuations; and (iii) a debriefing was held after the drills, which focused on the teachers' behavior (Table 4).

\section{RESULTS}

\section{Teachers' recognition of children's self-care abilities, which involves the children themselves preparing for disasters}

Teachers' recognition of the self-care abilities of children with physical disabilities or slight intellectual and 
Table 3 Status of the schools at the time of the Great East Japan Earthquake

\begin{tabular}{|c|c|c|c|}
\hline & $\begin{array}{l}\text { Measured Seismic } \\
\text { intensity }\end{array}$ & Main damage to school & Status of children \\
\hline School A & Just over five & $\begin{array}{l}\text { Walls cracked } \\
\text { Water pipes ruptured } \\
\text { School intercom system was disabled }\end{array}$ & $\begin{array}{l}\text { Most of the children had just finished preparing to return home } \\
\text { Wheelchairs that the children were in rolled around even } \\
\text { though teachers held them } \\
\text { All parents came to collect the children by approximately } 8 \mathrm{pm}\end{array}$ \\
\hline School B & Six & $\begin{array}{l}\text { Electricity, gas and water supply stopped } \\
\text { Tiles in the bathrooms broke and fell off } \\
\text { Air-conditioning ducts and ceilings } \\
\text { collapsed in several classrooms } \\
\text { and in the gym }\end{array}$ & $\begin{array}{l}\text { Children could not hide beneath desks } \\
\text { Some children were on the school bus but still on the school } \\
\text { grounds } \\
\text { Parents came to collect their children in the middle of the night } \\
\text { (except for two children who stayed overnight in the } \\
\text { dormitory) }\end{array}$ \\
\hline School C & Six & $\begin{array}{l}\text { Electricity, gas and water supply stopped } \\
\text { Roof the bus garage collapsed } \\
\text { Cracks appeared in the exterior walls of } \\
\text { the school building }\end{array}$ & $\begin{array}{l}\text { Children were evacuated to the school playground after the } \\
\text { shaking stopped } \\
\text { Children could have some snacks that teachers had kept in } \\
\text { their desks } \\
\text { Children were able to stay calm and wait for their parents to } \\
\text { collect them in the air-conditioned school buses; they had } \\
\text { gone home by approximately } 10 \mathrm{pm}\end{array}$ \\
\hline School D & Four & $\begin{array}{l}\text { Cracked and peeled walls } \\
\text { Emergency exit ramp broke away from } \\
\text { the exterior wall }\end{array}$ & Children had already gone home \\
\hline School E & Just under five & $\begin{array}{l}\text { Some walls collapsed outward and } \\
\text { others peeled } \\
\text { Small cracks appeared in the } \\
\text { foundations }\end{array}$ & All parents had come to pick up their children by midnight \\
\hline
\end{tabular}

Table 4 Disaster preparedness of the schools prior to the Great East Japan Earthquake

\begin{tabular}{|c|c|c|}
\hline & Stockpiles & Evacuation drills \\
\hline School A & $\begin{array}{l}\text { A day's worth of food, water for each child, according to the } \\
\text { 'Disaster Simulation Package for Special Needs Schools' } \\
\text { developed by researchers } \\
\text { Individual medicine for each child } \\
\text { No stockpiles for teachers }\end{array}$ & $\begin{array}{l}\text { Twice a year for an earthquake and fire } \\
\text { Once a year by watching an education program DVD } \\
\text { about disasters }\end{array}$ \\
\hline School B & $\begin{array}{l}\text { No stockpile of food, water, and individual medicine for either } \\
\text { the children or the teachers (a plan in progress) }\end{array}$ & Twice a year for an earthquake and fire \\
\hline School C & $\begin{array}{l}\text { No stockpile of food, water, and medicine for either children or } \\
\text { teachers }\end{array}$ & $\begin{array}{l}\text { Twice a year for an earthquake and fire, and this was } \\
\text { mandatory }\end{array}$ \\
\hline School D & $\begin{array}{l}3 \text { days' supply of food and water for both children and teachers } \\
3 \text { days' worth of individual medicine for children } \\
\text { Blankets }\end{array}$ & $\begin{array}{l}\text { Twice a year for an earthquake and fire } \\
\text { A practice run without students to reinforce the teacher's } \\
\text { roles }\end{array}$ \\
\hline School E & $\begin{array}{l}\text { Five to six meals and } 4 \mathrm{~L} \text { of water per one child from the } \\
\text { prefectural budget } \\
\text { Three meals and } 2 \mathrm{~L} \text { of water per one teacher prepared by } \\
\text { themselves } \\
\text { Blankets }\end{array}$ & $\begin{array}{l}\text { Twice a year for an earthquake and fire } \\
\text { Use of a picture-story show in small groups } \\
\text { A visit to a facility that provides training for earthquakes, } \\
\text { gale winds, and fire by simulators }\end{array}$ \\
\hline
\end{tabular}

physical disabilities were broken down into eight categories and 18 sub-categories (Table 5).

Each of the categories are indicated by box brackets [ ], sub-categories by angle brackets \langle\rangle , and what teachers said by quotation marks ',

\section{[Protecting themselves]}

Teachers recognized that the children in wheelchairs needed to protect themselves by (Protecting their head from damage $\rangle,\langle$ Applying wheelchair brakes $\rangle$ as there is a 
Table 5 Teachers' recognition of children's self-care abilities

\begin{tabular}{ll}
\hline [Categories] & Sub-categories $\rangle$ \\
\hline Protecting themselves & Protecting their head from damage \\
& Applying wheelchair brakes \\
& Asking for help \\
& Acting in accordance to instruction \\
& Recognizing dangerous situations \\
Sense of emergency & Sense of emergency from given instructions \\
Preparing emergency supplies & Preparing protection for the head \\
& Preparing supplies for survival \\
& Preparing items for personal psychological support \\
Asking for help & Asking for help \\
Acting in a calm way & Acting in a calm way without confusion \\
Acting independently & Preparation for life after school \\
& Handling unexpected circumstances \\
& Being self-reliant \\
Comprehending the situation of others and their surroundings too & What action to take away from school when others are around \\
Prior arrangement of means of contact in an emergency & How to act when alone \\
\hline
\end{tabular}

danger of wheelchairs moving uncontrollably, 〈Asking for help $\rangle$ when it is difficult for them to move by themselves, and also /Acting in accordance to instruction $\rangle$ after listening to the situation, and furthermore, 〈Recognizing dangerous situations〉 when they face difficulties in moving. If they could do that it could be life saving.

Teachers said 'Children cannot hide beneath desks to protect their heads from falling objects because they are in wheelchairs', and 'What children can do, just as an earthquake occurs, would be to engage the wheelchair brakes'. Also, 'They need to understand well what the teacher is saying before they can act'. Furthermore, 'Children need to be able to call out for help when they are incapable of moving; for example, being trapped by debris, etc.', and 'They need to recognize how dangerous their situation is, and that of the surrounding area also, when they are in Tsunami-risk areas'.

\section{[Sense of emergency]}

Teachers recognized that children needed the ability to understand an emergency by using their (Sense of emergency from given instructions $>$.

Teachers said 'Children can take teacher's instructions more seriously when the teacher talks sincerely to them. Children recognize they cannot act out of selfish thought'.

\section{[Preparing emergency supplies]}

Teachers recognized that for children with physical disabilities, it was not possible for them to move freely in a disaster, therefore, they needed to prepare for this by 〈Preparing protection for the head〉, 〈Preparing supplies for survival $\rangle$ and $\langle$ Preparing items for personal psychological support $\rangle$ for life after a disaster.

Teachers said 'Children need to prepare some kind of head protection', and 'Children must prepare their own survival items for situations like not being able to use lights, gas, and water, like in the great earthquake in 2011'. Also, 'They would be fine if they had some personal items to help them stay calm'.

\section{[Asking for help]}

Teachers recognized that children would need experience in $\langle$ Asking for help $\rangle$ from various people.

Teachers said 'Children having physical disabilities need someone's help to maintain their daily life. It is important that children can accept care from anyone'.

\section{[Acting in a calm way]}

Teachers recognized that children needed to acquire the ability of 〈Acting in a calm way without confusion〉.

Teachers said 'Children need to listen to teacher's instructions without becoming upset'.

\section{[Acting independently]}

Teachers recognized that children needed to have 〈Preparation for life after school〉 to gain the ability to act alone for not only for their school life but also for their future, by 〈Handling unexpected circumstances〉 when they do not expect them. Also, they recognized that 
children appeared $\langle$ Being self-reliant $\rangle$ because they were used to being helped, and to know /What action to take when away from school when others are around $>$ and 〈How to act when alone〉 because natural disasters can occur wherever they might be.

Teachers said 'Children have to learn to act with a degree of self-dependence for life after finishing school. They need to learn this because they have little opportunity of getting support in the community even though they have disabilities'. And 'They need to be able to deal with unexpected situations'; also, 'They need to get used to doing things by themselves because they are currently accustomed to receiving help from others, such as being pushed in a wheelchair'. Furthermore, 'Children might be on their way to or from school when a disaster strikes' or 'Children might be alone at home when a disaster strikes'.

[Comprehending the situation of others and their surroundings too]

Teachers recognized that children needed to be able to not only recognize their own situation but also 〈Comprehending the situation of others and their surroundings too $\rangle$.

Teachers said 'Children should think not only about their own situation at school, but also that of their families' situation, etc.'.

[Prior arrangement of means of contact in an emergency]

Teachers recognized that it was necessary for the children to have a concrete means of communicating in a disaster by knowing $\langle$ How to use e-mail $\rangle$.
Teachers said 'Some children can use e-mail from a mobile phone, so they can learn to ask for help and let others know their situation by sending texts'.

\section{Teachers' recognition for enhancement of child- ren's abilities through education}

Teachers' recognition of the ways for enhancing children's abilities through education were broken down into five categories and 18 sub-categories (Table 6).

\section{[Realistic simulation experiences]}

Teachers recognized that children needed 〈Realistic experiences through an earthquake simulation machine), 〈Specific evacuation drills〉, 〈Experience of staying overnight at school〉, 〈Actual use of their own emergency supplies $\rangle,\langle$ Actual simulation practice $\rangle$ and $\langle$ Eating foods not normally eaten $\rangle$.

Teachers said 'Children need realistic experiences of an earthquake through a simulation machine', and 'Children need evacuation drills which are simulated specific to their situations'. They also proposed that 'Children need to stay overnight at school' and that 'Children need to lay a blanket over themselves because they would have the possibility of staying at school'. Also, 'Children need drills to simulate a variety of actual situations' and finally, 'Children should experience eating foods they do not normally have'.

\section{[Repeated drills]}

Teachers recognized that children needed /Repetition of the same drills $\rangle$, experience with $\langle$ Repeated evacuation

Table 6 Teachers' recognition for enhancement of children's abilities through education

\begin{tabular}{ll}
\hline [Categories] & $\langle$ Sub-categories $\rangle$ \\
\hline Realistic simulation experiences & Realistic experiences through an earthquake simulation machine \\
& Specific evacuation drills \\
& Experience of staying overnight at school \\
& Actual use of their own emergency supplies \\
& Actual simulation practice \\
& Eating foods not normally eaten \\
& Repetition of the same drills \\
Repeated drills & Repeated evacuation drills in small groups \\
& Increased frequency of evacuation drills \\
& Shopping for emergency supplies \\
A variety of experiences & Experiencing different circumstances \\
& Increased exposure to being with strangers \\
& Experiencing various ways of escape and moving around \\
Experience listening to emergency & Listening to teachers give emergency instructions in different tones of voice \\
broadcasts and related instructions & Listening to teachers give emergency instructions with different facial expressions \\
Use of visual materials & Using television \\
& Using videos \\
& Using photos \\
\hline
\end{tabular}


drills in small groups〉 and an 〈Increased frequency of evacuation drills $\rangle$.

Teachers said 'We tried using a baby sling-like method of carrying children downstairs, but they disliked it. We feel that with continued practice, they would probably get used to it over time', and 'Repeated evacuation drills done in separate class groups or grade groups would be preferable'. Furthermore, 'We need to conduct evacuation drills many, many times for improved effectiveness'.

\section{[A variety of experiences]}

Teachers recognized that children needed to experience 〈Shopping for emergency supplies〉, be exposed to 〈Experiencing different circumstances , have an 〈Increased exposure to being with strangers $>$ and being exposed to Experiencing various ways of escape and moving around $\rangle$.

Teachers said 'Children need to shop for emergency goods' and 'They need to experience being in different places to their regular life because the impact of such a disaster would be very large'. Also, 'It is necessary for the children to increase their exposure to being around strangers'. Furthermore, 'Children need to experience various settings that make them think about how to escape from difficult situations and move around alone'.

[Experience listening to emergency broadcasts and related instructions]

Teachers recognized that children needed experience in (Listening to teachers give emergency instructions in different tones of voice〉 and 〈Listening to teachers give emergency instructions with different facial expressions $\rangle$.

Teachers said 'Children need to experience the teacher giving emergency instructions through the teacher changing their tone for the children to understand the seriousness of the situation' and 'Children need to experience the teacher giving emergency instructions and the teacher changing their facial expressions for the children to understand the seriousness of the situation'.

\section{[Use of visual materials]}

Teachers recognized that children needed experience in $\langle$ Using television $\rangle\langle$ Using videos $\rangle$ and $\langle$ Using photos $\rangle$.

Teachers said 'Children having physical disabilities, which prevent them from moving, have difficulty imagining things, but by using their sight, it is easier for them to create an image in their mind and grasp the idea better'.

\section{DISCUSSION}

\section{Specific self-care abilities for preparing for natural disasters}

When a natural disaster occurs, the point has been raised that it is difficult for children with disabilities to express their intention, avoid danger, evacuate and live an irregular life (MEXT, 2012b). Many physically disabled children are in wheelchairs, so they have great difficulty or simply cannot get under their desk or get to higher ground in the event of a flood or tsunami (Ager, Stark, Akesson, \& Boothby, 2010). This is because they have difficulty moving around for self-protection when a natural disaster strikes. In this study too, it was found that those in wheelchairs could not get under their desks, and because the wheelchair brakes were not on at the time of the earthquake, their wheelchair started moving around uncontrollably. These situations pose new dangers for the children. Therefore, when an earthquake strikes, it is necessary for the children to acquire such self-care abilities as 〈applying wheelchair brakes〉. This is action that children using a wheelchair should take at the time of an earthquake.

It is believed important that children acquire not only the ability to escape from danger, but also the self-care ability to move around using a wheelchair by themselves if they are able to handle one at the time of an earthquake (CDC, 2011). It is also thought important for children who have never moved around by themselves to acquire the self-care ability to do so without help.

Children with disabilities cannot get under their desk, so it is important that children learn the ability to protect themselves by 〈protecting their head from damage〉 due to the high risk of falling materials and glass. In addition, children need to prepare emergency protective goods for 〈preparing protection for the head〉. It is important for children themselves to recognize which type of head protection is best for their specific situation and purchase it. In the event of an earthquake, using the item they themselves bought would directly connect to a feeling of self-protection.

However, the abovementioned self-care abilities focus on earthquakes. Further consideration is needed for selfcare abilities for [protecting themselves] from various other disasters. When children cannot evacuate by themselves or find someone who can help them, it is important for them to be able to ask for help for survival and safety in a variety of disaster situations. Additionally, further discussion is needed about children's physical disabilities and how they correspond with the various types of disasters, as well as which method of calling for 
help should be used (e.g., using a whistle or a personal emergency alarm); they then learn the appropriate use of such a device as a way of increasing their self-care abilities. Children have to decide what they need to do for their survival according to the situation they are in. Whether to evacuate to a safe place as quickly as possible or remain where they are is key to their survival.

As the result of a survey that was conducted after the Great Hanshin Earthquake disaster for parents of children with disabilities, outcomes included "want to teach them how to recognize danger, such as earthquakes or fire and escape', and 'teach them the need to obey directions and be patient' (MOK news, 1995).

After the Great East Japan Earthquake, the problems observed by teachers who worked at special support schools for children with physical disabilities were the frequency of children requesting assistance, and the increase in children asking for help with things that they could already do themselves. It was understood that the reason for this occurring was that the children received unnecessary help from those who came to the evacuation centers to help. These people naturally believed disabled people need extra assistance because of their disability. This unfortunately caused these problems for the children (Child Research Net, 2012).

Furthermore, there is a need for children to recognize the situation they have been placed in and understand what is required of them. In this study, and from the comments that teachers have made, it was suggested that once the children understand their situation, the acquisition of safe evacuation self-care abilities is necessary.

\section{Consideration of ways for children to acquire and/or enhance self-care abilities to prepare for natural disasters}

Of the five categories for acquiring and/or enhancing children's abilities, four categories are based on real experience education methods such as [Realistic simulation experiences], [Repeated drills], [A variety of experiences], and [Experience listening to emergency broadcasts and related instructions], and one category provides information using devices such as [Use of visual materials]. [Realistic simulation experiences] is part of the education that provides opportunities of simulated situations at the time of a disaster. Having [Realistic simulation experiences] must present opportunities for children with disabilities to recognize their situation and realize what action they should take in advance of such a disaster. It was reported that children who had experienced realistic experiences through an earthquake simulation machine could recognize what they needed to do in the event of an earthquake at the special support schools for physically and intellectually disabled children (Kamata, 2012). [Repeated drills] are practice drills simulating situations like those in a disaster and are repeated numerous times.

At the participant schools in this study, evacuation drills, in which all students participated, were conducted twice a year; once for an earthquake and once for a fire. It was reported that the children at these special support schools who received repeated evacuation drill practice learnt to protect their heads and evacuate to a safe place. Also, having practiced getting on and off the school bus repeatedly, children learnt to move in a calm, orderly manner (Kamata, 2012). As mentioned above, by repeating these evacuation drills, children with physical disabilities or slight intellectual and physical disabilities would not only take the necessary action expected, but they also acquired the abilities they needed in the event of a disaster and this gradually became an automatic response for them. Additionally, it has been reported by the MEXT (2012b) that by repeating these evacuation drills, it is expected to result in children being able to acquire self-care abilities.

Having [A variety of experiences] is important, as it is difficult for these children to experience things outside their usual daily life, so it is necessary for them to experience different circumstances and also increase their exposure to being with strangers in order to avoid having such experiences for the first time at the time of a disaster. This is expected to be an effective method. From a survey taken after the Great Hanshin Earthquake, comments from parents with disabled children included 'Survival skills need to be included in daily life' and 'Experience of outdoor life is needed to raise their awareness of how to live without the usual modern conveniences' (MOK News, 1995). It is necessary for these children to experience life other than the one they are used to in order to be able to endure such conditions should a disaster occur. [Experience listening to emergency broadcasts and related instructions] is particularly important for young children who have physical and intellectual disabilities to have so that they can grasp an understanding of such situations. It is believed that this would lead to them being able to learn what action they needed to take in the event of a disaster. [Use of visual materials] is necessary for these same children as they struggle to understand the situation through verbal directions. But with the use of visual materials, they are then able to better understand. Therefore, practice with such materials is vital for them to be able to respond appropriately in a disaster (Matsuse \& Kobayashi, 2008). 
In this study, it was found that it is necessary for these children to include and put into practice these methods as part of their daily life.

\section{Importance of proposing the necessity for chil- dren to develop self-care abilities in preparation for natural disasters}

In Japan, children with disabilities learn to personally involve themselves in situations to prepare for life by themselves in a class that promotes "independent activities", which aims to develop these children's independence. Examples of the class contents include: "Health maintenance", "Forming relationships", "Grasping ones environment", "Physical training", and "Communication" (National Institute of Special Needs Education, 2011). In addition, the 'School disaster prevention manual', published by the MEXT (2012b), proposes the development of a similar manual in each school. The manual was expected to encourage children to take personal action for ensuring their own individual safety as preparation for earthquake and tsunami disasters. However, there are no complete studies that cover all the self-care abilities that children require, including the necessity for acquiring and enhancing children's abilities for preparing for natural disasters by themselves.

In this study, teacher-led evacuation drills were conducted at the participant schools we researched, as was the case in a previous study (Matsuse \& Kobayashi, 2008). It is expected that adults will keep challenged children safe because they have disabilities. However, in Japan, where natural disasters frequently occur, those children may be affected by a natural disaster wherein their parents and/or teachers are not immediately available. It is of great urgency that conducting emergency evacuation drills and educating children to protect their own safety and life proactively needs to start.

We recognize that children with disabilities hold a potential for acquiring and enhancing their self-care abilities. In this study, it was deduced in one point of view that for physically challenged or slight intellectually and physically challenged children to be prepared with the necessary self-care abilities to cope during natural disasters, the current education and evacuation drill approach needs to be completely rethought.

\section{Limitations of the Study and Suggestions for Future Studies}

The deduced results mainly focus on what happens in the event of an earthquake, not the self-care abilities required to prepare for a variety of disaster situations. This was the limitation faced. Therefore, hereafter, further studies need to be conducted that involve different types of natural disasters and the particular characteristics of the areas that these disasters may occur in. Furthermore, consideration of the level of intellectual development of these children and the degree of their disability is also necessary. In order for these children to be more prepared with the necessary self-care abilities to cope during natural disasters, we intend to continue our research. Also, by using this study as a foundation, we intend to develop more practical evacuation drills and education manuals.

\section{ACKNOWLEDGMENT}

This study was supported by a Grant-in-Aid for Scientific Research (no. 23593328), from the Japan Society for the Promotion of Science.

\section{REFERENCES}

Ager, A., Stark, L., Akesson, B. \& Boothby, N. (2010). Defining best practice in care and protection of children in crisisaffected settings: a Delphi study. Child Development, 81, 1271-1286.

Baker, L. R. \& Baker, M. D. (2010). Disaster preparedness among families of children with special health care needs. Disaster Medicine and Public Health Preparedness, 4, 240-245.

Baker, M. D., Baker, L. R. \& Flagg, L. A. (2012). Preparing families of children with special health care needs for disasters: an education intervention. Social Work in Health Care, 51, 417-429.

Cabinet Office, Government of Japan. (2011). Disaster management in Japan by the Director General for Disaster Management. [Cited 15 Oct 2013.] Available from URL: http:// www.bousai.go.jp/1info/pdf/saiguipanf.pdf (in Japanese).

Centers for Disease Control and Prevention (CDC). (2011). People with special needs. [Cited 22 Aug 2011.] Available from URL: http://emergency.cdc.gov/disasters/earthquakes/disabilities.asp

Child Research Net. (2012). Children with disabilities in city disasters. [Cited 13 Oct 2013.] Available from URL: http:// blog.crn.or.jp/lab/06/14.html (in Japanese).

Disability Information Resources. (2011). A disabled person's mortality rate in the Great East Japan Earthquake. [Cited 1 Apr 2013.] Available from URL: http://www.dinf.ne.jp/doc/ japanese/law/promotion/m37/ref4-1.html (in Japanese).

Japan Child and Family Research Institute. (2013). School education (pp. 230-231). In: Almanac of data on Japanese children. Japan child and family research institute (Ed.), Tokyo: Chuo Publishing (in Japanese).

Kamata, T. (2012). Preparation, reinforcement, and protectionunderstanding earthquakes and tsunamis, an important life preservation drive. [Cited 11 Nov 2013.] Available from URL: http://www.pref.chiba.lg.jp/kyouiku/anzen/saigai-anzen/ documents/105chousei (in Japanese).

Kato, R., Komuro, K., \& Numaguchi, C. (2008). Disaster simulation package for special needs schools. [Cited 20 Oct 2013.] Available from URL: http://www.kyoritsu-wu.ac.jp/ education/activity/pdf/jap.pdf (in Japanese). 
Kato, R., Komuro, K., \& Numaguchi, C. (2012). Disaster simulation package for special needs schools. [Cited 20 Oct 2013.] Available from URL: http://www.kyoritsu-wu.ac.jp/ education/activity/pdf/eng.pdf

Matsuse, M. \& Kobayashi, Y. (2008). A study of a disaster drill system in schools for special needs education (intellectual disabilities). Journal of the Faculty of Education and Human Sciences, Yokohama National University. The Educational Sciences, 10, 51-61 (in Japanese).

Ministry of Education, Culture, Sports, Science and Technology, JAPAN: MEXT. (2012a). The present state of special support schools. [Cited 15 Oct 2013.] Available from URL: http:// www.mext.go.jp/a_menu/shotou/tokubetu/002.htm (in Japanese).

Ministry of Education, Culture, Sports, Science and Technology, JAPAN: MEXT. (2012b). School disaster prevention manual. [Cited 20 Oct 2013.] Available from URL: http://www.mext. go.jp/a_menu/kenko/qnzen/_icsfiles/2012/07/12/1 (in Japanese).

MOK News. (1995). The great earthquake. [Cited 3 Oct 2013.]
Available from URL: http:/hwbb.gyao.ne.jp/matsu1-pf/ saigai.htm (in Japanese).

Murray, J. S. (2011). Disaster preparedness for children with special healthcare needs and disabilities. Journal for Specialists in Pediatric Nursing, 16, 226-232.

Nagaoka, H. (2007). AVR technology evacuation drill system for mentally handicapped children. Journal of Human Environmental Engineering, 9, 94-95 (in Japanese).

National Institute of Special Needs Education. (2011). Contents of independent activities. [Cited 18 Nov 2013.] Available from URL: http://www.nise.go.jp/cms/13,3314,55,251.html (in Japanese).

Peek, L. \& Stough, L. M. (2010). Children within the context of disaster: A social vulnerability perspective. Child Development, 81, 1260-1270.

Tanaka, S. (2013). Issues in the support and disaster preparedness of severely disabled children in affected areas. Brain \& Development, 35, 209-213. 